\title{
Narrativas de profesores sobre el uso de tecnologías digitales de información y comunicación durante la pandemia: voces de Brasil
}

Ilane Ferreira Cavalcante
ilanecfe@gmail.com
Instituto Federal do Rio Grande do Norte (IFRN)
Natal, Brasil
https://orcid.org/0000-0002-1783-9879
João Paulo de Oliveira (IFRN)
iprussasce@gmail.com
Centro de Investigação em Educação e Psicologia da Universidade de Évora (CIEP-EU)
Évora, Portugal

Conceição Leal da Costa (Universidade de Évora) https://orcid.org/0000-0003-3299-6845

mcl@uevora.pt

Centro de Investigação em Educação e Psicologia da Universidade de Évora (CIEP-EU)

Évora, Portugal

Recebido: 10/março/2021 Aceito: 30/agosto/ 2021

\section{Resumen}

El presente estudio tiene como objetivo conocer y comprender aspectos del uso de las Tecnologías Digitales de la Información y la Comunicación (TDIC) en el contexto de la pandemia Covid-19 a partir de los informes de docentes de Educación Básica (Educación Primaria y Secundaria) en Brasil. Se sustenta en los estudios de Abrãao (2003), Passeggi; Souza; Vicentini (2011); y Costa y Cavalcante (2017) entre otros. Los pasos dados en el camino metodológico incluyeron la aplicación de un formulario electrónico con preguntas abiertas y cerradas, análisis de los datos mediante N-Vivo seguido de la interpretación de los resultados. El estudio señaló que el uso de las TDIC en Brasil tiene aspectos limitantes para promover la educación, ya que los docentes necesitan una formación adecuada y la mayoría de los estudiantes de las escuelas públicas no cuentan con la infraestructura adecuada.

Palabras clave: Educación y tecnologías. Formación de profesores. Prácticas pedagógicas. Narrativas de los professores

\section{Relatos de professores sobre o uso das tecnologias digitais da informação e comunicação durante a pandemia: vozes do Brasil}

\section{Resumo}

Tem como objetivo conhecer e compreender os aspectos do uso das Tecnologias Digitais da Informação e da Comunicação (TDIC) no contexto da pandemia Covid-19 a partir dos relatos de docentes da Educação Básica (Ensino Fundamental e Ensino Médio) no Brasil. Teoricamente, está embasado em estudos de Abrãao (2003), Passeggi; Souza; Vicentini (2011); e Costa e Cavalcante (2017), entre outros. Os passos trilhados ao longo do percurso metodológico incluíram a aplicação de um formulário eletrônico com questões abertas e fechadas, análise dos dados com recurso ao N-Vivo seguida da interpretação dos resultados. 
O estudo apontou que o uso das TDIC no Brasil apresenta aspectos limitantes na promoção ao ensino, visto que os professores precisam de formação adequada e grande parte dos alunos da rede pública não dispõe da infraestrutura adequada.

Palavras-chave: Educação e tecnologias. Formação de professores. Práticas pedagógicas. Narrativas de docentes.

\title{
Teachers' narratives about the use of digital information and communication technologies during the pandemic: voices from Brazil
}

\begin{abstract}
It aims to know and understand the aspects of the use Digital Information and Communication Technologies (DICT) in the context of the Covid-19 pandemic from the reports of teachers of Basic Education (Elementary and Secondary Education) in Brazil. It's based on the studies of Abrãao (2003), Passeggi; Souza; Vicentini (2011); and Costa and Cavalcante (2017), among others. The steps taken along the methodological path included the application of an electronic form with open and closed questions, analysis of the data using N-Vivo followed by the interpretation of the results. The study pointed out that the use of DICT in Brazil has limitative aspects on promoting education, since teachers need adequate training and most of the public school students do not have the adequate infrastructure.
\end{abstract}

Keywords: Education and technologies. Teacher's formation. Pedagogical practices. Teacher's narratives

\section{Introdução}

\author{
Stop. \\ A vida parou \\ ou foi o automóvel? \\ (Carlos Drummond de Andrade)
}

Paramos, o vai e vem das ruas, as viagens nacionais e internacionais, os encontros familiares, as festividades, os shows, as aglomerações em geral. Paramos involuntariamente. Paramos, uns mais, uns menos, dependendo da necessidade de sobreviver. Paramos com melhores condições em alguns lugares, sem condições nenhuma em outros, mas fomos obrigados a parar. "O mundo está agora numa suspensão. E não sei se vamos sair dessa experiência da mesma maneira que entramos. É como um anzol nos puxando para a consciência. Um tranco para olharmos para o que realmente importa." (KRENAK, 2020, p.12).

Paramos, mas as condições não se deram da mesma forma para todos. "As condições da pandemia nos impelem a considerar como os objetos estruturam e sustentam nossas relações sociais, encapsulando as relações de trabalho, mas também as condições de vida e morte que o trabalho, o movimento, a sociabilidade, o abrigo, implicam”. (BUTLER, 2020, p.3). 
As condições de cada país, de cada estado, de cada indivíduo diferem e essas diferenças são determinadas, em geral, por condições de classe e socioeconômicas. Evidentemente, imbuídas nessa divisão estão também as divisões de gênero e de etnia. $\mathrm{O}$ isolamento não é igual para homens e mulheres. Não é igual para heteronormativos e LGBTQI+. Os grupos sociais, já separados antes da pandemia, recebem impactos também diversos durante o isolamento. $\mathrm{O}$ aumento da violência doméstica, a diminuição da produção de conhecimento pelas mulheres. A ausência de recursos financeiros para os mais economicamente vulneráveis. "Quem arrisca sua vida enquanto trabalha? Quem trabalha até morrer? A mão de obra de quem é mal remunerada e, então, dispensável e substituível? Sob as condições de uma pandemia essas questões se intensificam.” (BUTLER, 2020, p. 5)

São situações que já existiam, porém, como afirma a filósofa Judith Butler, se intensificam com a pandemia. Se tornam mais cruciais, pois a pandemia atinge a todos, mas atinge de forma diferente a cada um. Isso já era claro em pandemias anteriores. A gripe espanhola atingiu de formas diferentes os países desenvolvidos e aqueles em desenvolvimento. A globalização, ampliada ao longo do século XX interfere diretamente na expansão do vírus. O neoliberalismo vem paulatinamente diminuindo o investimento em saúde nos países que assumiram a teoria do estado mínimo.

Aqueles com bons planos de saúde que também podem trabalhar ou ensinar de casa estão confortavelmente isolados, desde que sigam salvaguardas prudentes. Os funcionários públicos e outros grupos de trabalhadores sindicalizados com cobertura decente terão de fazer escolhas difíceis entre renda e proteção. Enquanto isso, milhões de trabalhadores com baixos salários, trabalhadores rurais, desempregados e sem teto estão sendo jogados aos lobos. (DAVES, 2020, p.9)

A pandemia parece deixar evidente a todos que a expansão do capitalismo precarizou as relações humanas, as relações sociais, as relações de trabalho e, pior, tornou quase biologicamente insustentável a permanência do ser humano no mundo. Mas isso nos levará a algum caminho novo? Só o tempo dirá, posto que, como o vírus, o capitalismo também se transforma, também se adapta, também encontra novos caminhos de manutenção do status quo. Para Bruno Latour:

Os adeptos da globalização, aqueles que, em meados do século XX, inventaram a ideia de escapar das restrições planetárias, também veem nela uma excelente oportunidade de se desvencilhar ainda mais radicalmente do que resta de obstáculos à sua fuga para fora do mundo. Para eles, essa é uma oportunidade boa demais de se livrarem do resto do Estado social, da rede de segurança dos mais pobres, do que ainda resta de regulamentação contra a poluição e, mais cinicamente ainda, de se livrarem de toda essa gente em excesso que atulha o planeta. (LATOUR, 2020, s.n) 
Ocorre que tanto há possibilidade de sair dessa grande crise global e globalizada de forma mais positiva, valorizando o bem estar social e humanizando as relações sociais (principalmente as relações de trabalho), investindo em uma economia mais "verde" como propõe Noam Chomsky, como há, por outro lado, uma possibilidade de sair ainda mais perigosamente neoliberal e capitalista, com a opção pela segregação dos mais pobres, tanto países quanto pessoas; ampliando as barreiras sociais e geográficas; minimizando os limites entre público e privado para o monitoramento de possíveis doenças, enfim, controlando a vida dos indivíduos. Os caminhos são ambíguos e possíveis. No entanto, há uma certeza: a realidade não será mais a mesma. Latour (2020, s.n) almeja uma mudança positiva:

O que o vírus consegue com a humilde circulação boca a boca de perdigotos - a suspensão da economia mundial - nós começamos a poder imaginar ser para nós também possível, que nossos pequenos e insignificantes gestos, acoplados uns aos outros, conseguirão: suspender o sistema produtivo.

O autor se ampara na solidariedade, na atuação conjunta, na união por um mundo melhor. Seria, possivelmente, a melhor saída. Mas, sendo outra a realidade, o que se sabe, de fato, é que ela exigirá novas formas de ação em todas as áreas. E essas formas começam ainda durante a pandemia.

A educação é uma das áreas que a crise atingiu de forma indelével e, provavelmente, permanente. Como lidar com a educação formal em tempos de pandemia? Como retornar à normalidade depois? São questões feitas diariamente e não há apenas uma resposta, pois cada solução depende das condições sociais, econômicas, culturais dos diferentes grupos.

Uma solução plausível e acalentada diariamente, com prós e contras, é o uso das tecnologias digitais da informação e comunicação (TDIC). A saída para a suspensão das aulas presenciais amparou-se imediatamente no uso das tecnologias. Para quem, no entanto, essa saída foi possível? Os professores sentiam-se preparados para ela? A quem essa solução atingiu? Os estudantes estavam preparados para essas novas formas de ensino? Perguntas como essas são geradas a partir da leitura das notícias, da análise das propostas de ação feitas pelas gestões da educação em todos os âmbitos (união, estados, municípios, iniciativas privadas).

Este artigo se debruça sobre a realidade brasileira acerca do uso das TDIC durante a pandemia. Ele traz resultados parciais de um estudo mais amplo que se ampara na parceria entre professores e pesquisadores do Instituto Federal de Educação, Ciência e Tecnologia do Rio Grande do Norte (IFRN) e do Centro de Investigação em Educação e Psicologia da 
Universidade de Évora (Portugal). Parceria estabelecida por meio do vínculo com o grupo de pesquisa em Multirreferencialidade, Educação e Linguagem (GPMEL), do IFRN.

\section{Reflexão sobre o uso das TDIC na educação brasileira}

Seguindo a tendência mundial, o Brasil interrompeu o funcionamento das escolas durante a pandemia. Grande parte das escolas privadas optou pelo ensino remoto, mas na educação pública a solução não tem sido simples. As redes estaduais têm feito um esforço no sentido de capacitar professores, disponibilizar atividades on-line e aulas ao vivo e por meio de redes sociais. No entanto, essa não tem sido uma tarefa fácil, nem para estudantes nem para professores.

Um breve passeio pelas páginas dos principais meios de comunicação já aponta o quanto é premente, durante a pandemia, o apelo ao uso das TDIC na Educação. No site da TV Brasil, um vídeo indica: "A educação em tempos de pandemia: realidade e desafios". 1 No sítio da principal emissora de TV brasileira, a manchete informa: "Tecnologia leva aulas a casas de estudantes de todo o Brasil durante a pandemia" ${ }^{2}$. No sítio de um dos maiores jornais do país: "Celular na educação: os desafios da pandemia"33 Por fim, no sítio de uma revista de grande circulação surge a pergunta: "Como a tecnologia pode ajudar nossas escolas a vencer o Coronavírus?"4. Aparentemente, as TDIC tornaram-se a panaceia que poderia indicar a superação da crise, mas não é bem assim, há obstáculos, há impossibilidades. Em uma realidade ideal, elas poderiam ser, de fato, um importante instrumento de manutenção dos estudos e estímulo à pesquisa, para evitar a suspensão total das atividades. E, de fato, para alguns, elas têm funcionado nesse sentido. Que obstáculos, no entanto, são perceptíveis nesse processo?

Algumas pistas dos obstáculos podem ser percebidas nos dados oficiais do Brasil. $\mathrm{Na}$ sinopse estatística do censo escolar publicado em 2019, o INEP informa que as escolas de ensino fundamental começaram a apresentar recursos tecnológicos de forma ainda tímida, pois pouco mais de $50 \%$ das escolas possuem projetor digital e apenas $34,3 \%$ possuem computadores de mesa. Já internet para uso dos estudantes está presente em apenas $21,1 \%$

\footnotetext{
1 Disponível em https://tvbrasil.ebc.com.br/sem-censura/2020/04/educacao-em-tempos-de-pandemiarealidade-e-desafios Acesso em 17 de maio de 2020.

2 Disponível em https://g1.globo.com/jornal-nacional/noticia/2020/04/18/tecnologia-leva-aulas-a-casas-deestudantes-de-todo-o-brasil-durante-a-pandemia.ghtml Acesso em 17 de maio de 2020.

3 Disponível em https://www1.folha.uol.com.br/educacao/2020/04/celular-na-educacao-os-desafios-dapandemia.shtml Acesso em 18 de maio de 2020.

4 Disponível em https://exame.abril.com.br/blog/crescer-em-rede/como-a-tecnologia-pode-ajudar-nossasescolas-a-vencer-o-coronavirus/ Acesso em 18 de maio de 2020.
} 
das escolas. (INEP, 2019) Essa é a realidade da escola pública de ensino fundamental. A escola que atinge a maioria da população brasileira, justamente aquela população que também não possui renda suficiente para adquirir esses itens para uso pessoal, em suas residências.

Embora o acesso à internet tenha aumentado, chegando a 79,9\% da população, conforme dados apresentados pelo Instituto Brasileiro de Geografia e Estatística (IBGE) ${ }^{5} \mathrm{em}$ 2018, esse acesso se dá em condições inadequadas, posto que uma parcela ainda imensa (26,5\%) vive abaixo da linha da pobreza. No Nordeste esse contingente chega a 44,8\%. Um expressivo contingente amarga a vida em moradias sem acesso a saneamento $(35,7 \%)$ e $13 \%$ vivem em residências com adensamento excessivo (mais de três moradores por dormitório). Um dado muito relevante é ainda o fato de ter aumentado a distância entre pobres e ricos, os $10 \%$ mais ricos da população acumulam $43,1 \%$ da massa total de rendimentos, enquanto os $40 \%$ mais pobres detêm apenas $12,3 \%$ desses rendimentos. O Brasil é, portanto, um país extremamente desigual. E essa desigualdade se reflete na educação.

O contexto é importante para lembrar que não basta ter acesso à internet, é preciso ter os recursos necessários para estudar por meio da web e, para isso, se faz necessário um local para estudo, o mínimo de silêncio, uma banda larga de qualidade para a recepção de áudios e vídeos. É importante observar, por exemplo, que embora 79\% dos estudantes da rede pública tenham acesso à web, esses estudantes acessam a rede prioritariamente por meio de celular, um recurso que não é o ideal para pesquisas, realização de tarefas ou mesmo ensino remoto. A realidade dos estudantes de escolas particulares é diametralmente oposta, pois $96,6 \%$ deles tem acesso à internet e, embora o celular seja de uso generalizado, 75,2\% deles tem computador em casa e $32,7 \%$ contam com tablets. Na rede pública, apenas $35,6 \%$ têm acesso a computador no domicílio e 9,1\% têm acesso a tablets (IBGE, 2018), como pode ser observado na Tabela 1, a seguir.

Tabela 1 - acesso a recursos tecnológicos digitais

\begin{tabular}{|c|c|c|c|c|c|c|}
\hline Rede de ensino & INTERNET & $\begin{array}{l}\text { COMPUTADOR } \\
\text { CASA }\end{array}$ & EM & $\begin{array}{l}\text { TABLET } \\
\text { CASA }\end{array}$ & EM & CELULAR \\
\hline Pública & $78,7 \%$ & $35,6 \%$ & & $9,1 \%$ & & $98,9 \%$ \\
\hline Privada & $96,6 \%$ & $75,2 \%$ & & $32,7 \%$ & & $99,3 \%$ Fonte \\
\hline
\end{tabular}

Fonte: PNAD Contínua Anual 2018 (IBGE). Elaboração própria

\footnotetext{
${ }^{5}$ Dados disponíveis em https://agenciadenoticias.ibge.gov.br/agencia-sala-de-imprensa/2013-agencia-denoticias/releases/23298-sintese-de-indicadores-sociais-indicadores-apontam-aumento-da-pobreza-entre-2016e-2017 Acesso em 18 de maio de 2020.
} 
Os dados não mencionam a variação por região, que também é enorme, mas já deixa evidente que não há soluções fáceis, ou mesmo homogêneas possíveis para as diferentes realidades do país. Dessa forma, pode-se ter crianças de ensino infantil tendo acesso a ensino remoto $^{6}$ contínuo em sua casa, acompanhado pelos pais nas classes mais favorecidas, mas essa é uma realidade de apenas uma parcela da população. A maioria se revela sem acesso ou com um acesso irregular e sem condições ideais de concentração, acompanhamento e estudo. Os relatos dos docentes apresentados nos tópicos seguintes deste artigo corroboram os dados aqui apresentados.

Se a realidade dos estudantes é desigual, a dos professores não é diferente, pois as condições de acesso também variam. As condições de salário dos professores também não são homogêneas em todo o território nacional e varia conforme a rede em que atua (municipal, estadual, federal, particular) e conforme a região, pois o piso salarial não é regularmente pago por todas as esferas e as condições de trabalho e carreira variam de acordo com a legislação local.

Nesse contexto, o acesso, o uso e a familiaridade com os recursos tecnológicos digitais são maiores ou menores conforme os diversos fatores intrínsecos e extrínsecos aos indivíduos. Evidentemente, o país investiu em infraestrutura tecnológica, mas não o suficiente e esse investimento praticamente parou com as crises políticas que precederam e sucederam o golpe de 2016. A pandemia não trouxe avanços nesse quadro. Muito pelo contrário, na contramão de todo o mundo, o Brasil tem um governo que investe no caos e no desbaratamento das poucas ações positivas elaboradas pelos órgãos devotados à saúde e à educação.

As redes estaduais são as que mais têm envidado esforços no sentido de prover tanto professores (com acesso a capacitações para uso das TDIC na educação) como estudantes, embora não possa garantir o acesso destes às atividades e plataformas utilizadas, o que torna complexo o processo de oferta de ensino remoto. A nota técnica do movimento Todos pela Educação informa, em gráfico, o esforço das redes estaduais no sentido do ensino remoto.

\footnotetext{
${ }^{6}$ Aqui vale uma explicação sobre a diferença entre ensino remoto e educação a distância no âmbito do que vem sendo desenvolvido no Brasil. O ensino remoto simula a aula presencial tendo por meio um recurso tecnológico, uma plataforma de videoconferência, por exemplo. Já a Educação a Distância é uma modalidade regulamentada por lei, requer um planejamento prévio, uma estrutura e material didático específicos e plataformas que possibilitem a interação síncrona e assíncrona.
} 
Gráfico 1 - estratégias das redes estaduais para oferta de ensino

\subsection{ESTRATÉGIAS DAS REDES ESTADUAIS ATÉ O MOMENTO}

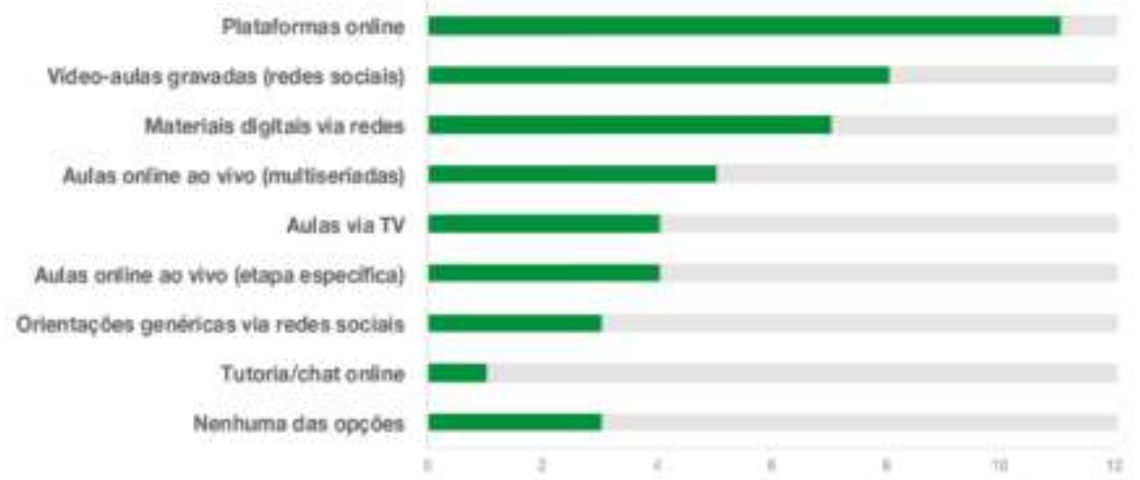

Fonte: Nota técnica: Ensino a Distância na Educação Básica Frente à Pandemia da Covid-19 (2020)

Fruto da iniciativa privada e sob uma perspectiva neoliberal, a nota técnica do movimento Todos pela Educação aposta no ensino remoto como uma forma de prover os estudantes de algum recurso para manutenção dos estudos durante a pandemia. No entanto, de nada adiantam os esforços de oferta se a realidade desses estudantes não permite o acesso aos materiais e às aulas on-line. O próprio documento, aliás, alerta para o fato de que é necessário considerar a limitação desse acesso e realizar um planejamento cuidadoso, além de normatização adequada, pois o uso desses recursos, ao invés de promover a igualdade, pode operar em sentido inverso, desenvolvendo as desigualdades.

Dessa forma, não se trata de ser contra ou a favor do uso das TDIC na educação, não se trata de perceber sua viabilidade, mais que comprovada quando se pensa na educação a distância pública realizada já ao longo de uma década no Brasil. Trata-se, na verdade, de perceber que não há formação sem a presença e sem o acesso dos estudantes. Sem garantir esse acesso, não há solução.

\section{A pesquisa autobiográfica e a compreensão da realidade dos sujeitos docentes}

O relato biográfico é tanto instrumento de formação quanto um instrumento de investigação, pois "O sujeito, ao narrar sua vida, relaciona fatos e acontecimentos a um contexto específico e, ao fazê-lo, a transforma em uma história de vida, mediante uma construção partilhada com o pesquisador." (FRISON; SIMÃO, 2011, p.198). O sujeito que narra e o pesquisador compartilham, portanto, da realidade que se constrói a partir da narrativa. 
A pesquisa autobiográfica tem se desenvolvido de forma cada vez mais frequente na área da educação por permitir, a partir dos relatos, a construção de uma perspectiva histórica (pessoal e social) que é possível ao analisar os contextos extraídos dos relatos.

Já que esse tipo de pesquisa, conforme lembram Cavalcante e Costa (2017), traz a possibilidade de construção de saberes singulares, apreendendo a temporalidade da vida e a construção partilhada do saber. Nesse sentido, buscamos as relações entre ensino, aprendizagem, subjetividade e reflexividade sistemática, para as promovermos, deixando que hétero e autocompreensão biográficas tomem lugar e definindo a última como "a capacidade de criatividade humana para reconstituir a consciência histórica das aprendizagens realizadas ao longo da vida" (PASSEGGI; SOUZA; VICENTINI, 2011, p. $372)$.

A pesquisa biográfica pode ocorrer por meio de diversos instrumentos (memórias, narrativas, relatos orais, histórias de vida, biografias, entre outros), assim como também pode contar com fontes diversificadas (filmes, diários, cartas, documentos em geral, inclusive aqueles que circulam por meio das TDIC).

Trabalhando com essas possibilidades, o pesquisador assume a postura de reconhecer que a realidade social é múltipla e, portanto, permite a pluralidade de perspectivas com que os diferentes indivíduos a constituem a partir de suas subjetividades. Dessa forma, Abrahão (2003, p.80) afirma: "Nesta tradição de pesquisa, o pesquisador não pretende estabelecer generalizações estatísticas, mas, sim, compreender o fenômeno em estudo, o que lhe pode até permitir uma generalização analítica."

Tentando compreender a realidade dos docentes da Educação Básica no Brasil um grupo de pesquisadores procurou compreender a experiência dos professores por meio de suas respostas a um questionário elaborado e aplicado on-line. Neste artigo, trazemos a reflexão acerca dos aspectos que emergiram sobre a realidade brasileira.

\subsection{A experiência de docentes durante a pandemia}

A pesquisa aqui relatada foi realizada durante os meses de maio e junho de 2020 no Brasil. Para a consulta aos professores foi elaborado um questionário no Google forms aplicado a professores da educação básica (ensino fundamental e médio) das redes públicas e privadas, com exceção dos professores da Rede Federal de Educação Profissional e Tecnológica (EPT) por compreender que as condições imediatas de acesso e uso de tecnologia é mais corrente entre esses professores. O objetivo do questionário é compreender 
o uso das tecnologias digitais realizado por professores de escolas públicas das redes estaduais e municipais e que, ocasionalmente, também atuam nas escolas privadas em suas regiões. Os professores das escolas públicas, muitas vezes, são os mesmos das escolas particulares, no entanto, os estudantes não têm as mesmas condições de acesso e utilização de infraestrutura tecnológica, dada a desigualdade estrutural do país, como o demonstram, inclusive, alguns dos dados apresentados nos tópicos anteriores deste artigo.

O questionário foi aplicado no Brasil com ênfase no estado do Rio Grande do Norte, mas alcançou outros estados, por meio do compartilhamento feito nas redes sociais. Em dois dias alcançou o total de 99 respondentes de estados como Rio Grande do Norte, Pernambuco e Roraima, compreendendo realidades da região Norte e Nordeste. Com o número já satisfatório de respondentes para os objetivos dos pesquisadores naquele momento, o questionário foi fechado.

O questionário apresentou 6 questões abertas e 10 questões fechadas. que. As questões abertas buscavam esclarecimentos sobre as respostas dadas a algumas das questões fechadas e suscitavam relatos e reflexões sobre a vivência dos respondentes durante a pandemia, assim como procuraram compreender sua interação com os recursos tecnológicos na educação antes e durante a pandemia, solicitando-lhes indicar os aspectos positivos e negativos desse uso durante o momento de isolamento e suspensão das aulas por que passavam. As questões fechadas foram organizadas em escala que variava de discordo totalmente a concordo totalmente buscaram compreender o perfil profissional dos respondentes e estabelecer a rede de atuação, o uso dos recursos tecnológicos na educação antes e durante a pandemia, o nível de ensino prioritário de atuação dos professores participantes.

Para a análise das respostas às questões abertas do questionário foi utilizado o software N-Vivo. A análise de conteúdo de Bardin (2011) foi a base para a construção das categorias, que emergiram a partir dos discursos dos docentes. Passemos à apresentação e análise dos relatos docentes.

\subsection{Vozes do Brasil}

Os noventa e nove respondentes do questionário são professores da Educação Básica das redes municipais e estaduais de várias regiões do país, com ênfase para Norte e Nordeste (há apenas dois respondentes do Rio Grande do Sul). A maioria também é professor de escolas públicas, apenas dois respondentes informaram ser professores de escolas 
particulares e dois informaram ser professores de escola pública e particular concomitantemente. $\mathrm{O}$ foco desta pesquisa, portanto, se debruça sobre a realidade da escola pública, embora haja relatos que estabeleçam um contraponto com a realidade de estudantes de escolas particulares.

Os níveis de atuação variam, com vários respondentes atuando em mais de um nível de ensino, prioritariamente o Ensino Fundamental, onde atuam 45 dos respondentes, principalmente nos anos finais desse nível: $6^{\circ}$ a $9^{\circ}$ anos. 33 respondentes atuam no Ensino Médio, alguns deles atuam em mais de um nível de ensino. Alguns respondentes incluíram sua atuação na Educação Infantil (5 participantes), na Educação Superior (3 participantes), no EJA fundamental (três participantes), mas o foco da pesquisa se dará sobre os relatos dos respondentes acerca de sua atuação no Ensino Fundamental e Médio, por ser a área de atuação da maioria.

A pesquisa ainda demonstra que $79,8 \%$ dos professores já utilizavam as tecnologias digitais, pois $55,6 \%$ responderam que utilizava diariamente e $24,2 \%$ utilizavam semanalmente as tecnologias no seu cotidiano antes da pandemia. No entanto, a resposta não é igual quanto ao uso das tecnologias na docência. Nesse caso, diante da pergunta: "Utilizava com facilidade as Tecnologias Digitais da Informação e Comunicação (TDIC) na atuação docente antes da pandemia?" 49,5\% responderam que concordava parcialmente, 18,2\% que discordava parcialmente e apenas $26,3 \%$ concordavam totalmente com a facilidade do uso das TDIC na docência. As respostas levam a crer que, apesar de familiarizados com o uso das tecnologias para os aspectos da vida pessoal, os professores ainda não demonstram total envolvimento com seu uso para o exercício da docência, pois apenas 49,5\% demonstraram utilizá-las para a docência antes da pandemia.

Ao serem questionados sobre a necessidade de uso das TDIC para dar aulas a distância durante a pandemia, 43,4\% informaram concordar totalmente com essa necessidade, enquanto $29,3 \%$ informaram concordar parcialmente, o que significa que a ampla maioria sentiu a necessidade de utilização das TDIC para o exercício da docência durante a pandemia. Dessa forma, os dados indicam que os professores sentiram a necessidade de utilizar as TDIC nas aulas durante a pandemia, apesar da totalidade não costumar usá-las para isso antes da pandemia, conforme respostas à pergunta anterior. 50,5\% dos docentes concordaram totalmente com a questão sobre utilização das TDIC para elaboração de atividades para os estudantes, enquanto $31,3 \%$ afirmaram que concordavam parcialmente com essa utilização, o que pode indicar que tenham elaborado outros recursos 
além de atividades. Apenas 13,1\% dos docentes discordaram totalmente dessa questão, indicando que não utilizaram as TDIC para elaboração de atividades para seus estudantes.

Quando questionados se receberam ou fizeram alguma capacitação para uso das TDIC na sua atuação docente, $84,8 \%$ informaram que não tiveram acesso a nenhuma capacitação. Esse item transparece nos relatos dos docentes, que reclamam a necessidade de formação para uso das TDIC na educação. Os 15,2\% que afirmaram ter passado por capacitação, tiveram experiências diversas, desde reuniões de uma tarde a treinamentos, capacitações on-line e cursos ofertados por instituições e empresas.

Ao considerarem o acesso dos estudantes às atividades oferecidas por meio das TDIC, $47,5 \%$ dos professores responderam que menos de $50 \%$ dos estudantes acessam os recursos; $24,2 \%$ responderam que $50 \%$ dos estudantes acessam as atividades e 18,2\% não sabe se os estudantes acessam as atividades. Os dados indicam, portanto, que a maioria dos estudantes não acessa com facilidade as atividades veiculadas por meio das TDIC. Esse é outro elemento que transparece com frequência na maioria dos relatos dos professores.

Ao realizar a leitura dos relatos elaborados a partir das duas questões abertas, os dados apresentados nas questões fechadas se estabelecem e novas nuances podem ser observadas quanto ao uso das TDIC no contexto da pandemia no Brasil.

A análise dos relatos demonstrou algumas ideias recorrentes que geraram duas grandes categorias de análise: $\mathrm{O}$ uso das tecnologias durante a pandemia e a Capacitação. A primeira grande categoria demonstrou que o uso das tecnologias durante a pandemia apresentava duas perspectivas, tidas como subcategorias: aspectos positivos e aspectos negativos desse uso. Dessa forma, os relatos são analisados seguindo essa divisão.

\subsubsection{O uso das tecnologias durante a pandemia: aspectos positivos}

Em geral, os professores demonstram não ter tido dificuldades quanto ao uso das tecnologias para elaboração de atividades para seus estudantes, no entanto, os aspectos positivos desse uso não se descolam dos aspectos negativos, pois todos os relatos apontaram que esses aspectos estão relacionados de forma intrínseca, um dependendo do outro. A divisão que aqui se apresenta é realizada apenas a título de análise.

Os aspectos positivos elencados quanto ao uso das tecnologias compreendem a ampliação dos conhecimentos:

Como prof de língua inglesa já faço o uso das tecnologias, entretanto agora aprendi utilizar outros aplicativos e novos recursos digitais. (INF. 8) 
Todos precisamos utilizar a tecnologia para "dar" aulas a distância. Eu consegui utilizar algumas tecnologias como o WhatsApp, google forms (INF. 15)

Necessitei utilizar as TDIC para gravar vídeo aulas, para pesquisar novas formas de avaliar e de proporcionar um aprendizado mais significativo para os meus alunos (INF. 19)

No meu caso, estou utilizando o Google Classroom. Trata-se de uma plataforma de fácil acesso, bastante intuitiva, que possibilita inserir vídeos, imagens, documentos e elaborar atividades variadas. Apesar de nunca tê-la acessado antes, não foi difícil criar as salas e elaborar as atividades. $\mathrm{O}$ estado tem dado suporte em forma de videoaulas que passam na TV e também criou um canal no YouTube com esses vídeos. Com o surgimento dessa doença, este foi a única possibilidade que nos restou na educação (INF. 29)

Tem sido desafiador. Aspectos positivos com relação a profissão docente, seria a possibilidade do reinventar a docência e assim impulsionar a profissionalidade docente. Positivo com relação ao alunado seria a possibilidade desde aluno aprender a se organizar e ter um tempo de estudo em casa. (INF. 50)

Os relatos apresentados demonstram que o uso das tecnologias durante a pandemia se deu por necessidade ou imposição das redes de ensino, implicando em novos conhecimentos e novas práticas de ensino para esses docentes. Os professores relatam que esse aprendizado com o uso das tecnologias tem se demonstrado algo relevante para si mesmos e para os estudantes que acessam o material e os recursos disponibilizados:

São importantes, pois elas facilitam a comunicação entre professor e aluno, facilitando o aprendizado e a prática didática diária do professor. É um instrumento facilitador que só tem a somar no aprendizado. (INF. 31)

$\mathrm{Na}$ atual conjuntura desta triste situação de Pandemia é de estrema necessidade que o professor lance de todo recurso tecnológico para poder ministrar suas aulas a distância, seja através de videoconferência ou vídeo aula gravada através de plataformas disponíveis, no caso da matemática o Geogebra é de suma importância e outros. (INF. 49)

Estou fazendo uma experiência com os meus alunos da escola Municipal. Como a maioria deles tem acesso a um celular ou conseguem utilizar o de alguém da família. Quando começou a pandemia aqui no munícipio de Natal e precisamos entrar em quarentena, fiquei angustiada, pois gosto muito de dar aula, de estar com eles, mesmo com toda dificuldade de indisciplinas, desinteresses, dificuldades cognitivas entre outros. Mas de algum modo conseguimos nos aproximar e acender aquela chama interna, uma luz que se reflete nos olhos deles e mais ainda nos meus quando conseguimos juntos atingir os nossos objetivos. Diante disso e ciente dos grupos por turmas, constituídos pelas gestoras administrativa e pedagógica via WhatsApp. Solicitei a elas que me adicionasse nos grupos. Então desde o dia 18/03/2020 venho por meio desse canal de comunicação, desenvolvendo semanalmente atividades no livro, material didático individual que todos têm acesso, pesquisas, experimentos análises de vídeos, produção de pequemos vídeos e áudios sonoros, questionários entre outros. Após a postagem das atividades por turmas os alunos se comunicam comigo no próprio grupo ou no privado, me enviam as atividades via WhatsApp ou por e-mail. E, assim vamos já na nona semana recheadas de experiências e uma vivência inusitada para professora. Quanto ao interesse dos alunos, acho muito parecido com o da sala de aula, os mais dedicados perguntam, debatem, fazem e me enviam as atividades. Os outros precisam de um estímulo. Como sempre, vale quanto professora. Para mim está sendo muito gratificante preenchendo o vazio deixado pela distância da escola. (INF. 52) 
O informante 52 dá um relato detalhado dos aspectos que envolvem a utilização das tecnologias durante a pandemia, demonstrando um dado importante: a maioria dos seus estudantes têm acesso às redes sociais específicas, possíveis de ser acessadas com recursos de baixa qualidade da rede, com ênfase na rede social de troca de mensagens WhatsApp. Esse é o recurso utilizado por parte dos docentes dada a universalização de seu uso entre os estudantes. Sua experiência é com estudantes de Ensino Fundamental, visto que relata experiência em escola Municipal e informa que, mesmo quando os estudantes não possuem um celular próprio, têm acesso a um celular de algum membro da família. Esse relato corrobora os dados apresentados em tópico anterior que apresentam os dados de acesso a recursos tecnológicos entre estudantes de escolas públicas, o recurso mais utilizado pelos estudantes é o celular. Esse recurso, embora fundamental para a comunicação, pode não ser o mais adequado para leitura, estudo e pesquisa. $\mathrm{O}$ relato do informante 52 é positivo quanto a esse uso.

Um contraponto interessante a esse dado é que, conforme o gráfico 1, apresentado em tópico anterior deste trabalho, o maior esforço das secretarias estaduais de educação no país está se dando no uso das plataformas digitais, o que pode ser, eventualmente, um problema para os estudantes cujo acesso se dá prioritariamente por celular. Nem sempre essas plataformas possuem recursos para mobile. Outros relatos trazem, ainda, soluções acerca da integração entre as tecnologias digitais e as tecnologias já tradicionais no cotidiano escolar:

Eu elaboro atividades e envio para a escola e para o grupo de WhatsApp dos pais de alunos. Quem não pode imprimir vai até a escola e pega com a secretaria uma cópia das atividades. (INF. 53)

Utilizei como utilizava anteriormente, como orientações de estudo, um estudo dirigido. Utilizei na rede de ensino pública municipal. (INF. 54)

Os professores informantes deixam evidente que é possível integrar soluções que extrapolam as tecnologias. Os estudantes que não tenham acesso às atividades por meio das tecnologias poderiam ir buscá-las impressas na escola. No entanto, o Informante 53 lembra: "Nem todos os pais de alunos se interessam em buscar as atividades. Apenas 30\% estão interessados". Considerando as restrições de circulação durante a pandemia e os riscos de contágio, essa ida à escola também pode implicar em obstáculos como as condições socioeconômicas e as relações familiares. No caso de estudantes que moram distante das escolas, se faz necessário o deslocamento dos pais até a escola para receber as atividades, visto serem estudantes de Ensino Fundamental, ainda crianças. Isso demanda recursos financeiros e interesse dos familiares em manter o vínculo com a escola durante o 
isolamento. Esse acesso, para além das tecnologias, é viável, mas também implica em dificuldades e risco para os estudantes e seus familiares, portanto, o acesso dos estudantes é aspecto fundamental no que tange aos aspectos negativos do uso das tecnologias como se pode observar no tópico a seguir.

\title{
2.2.2 $\mathrm{O}$ uso das tecnologias durante a pandemia: aspectos negativos
}

No que tange aos aspectos negativos do uso das tecnologias, a maioria dos professores abordou a dificuldade dos estudantes no acesso às tecnologias, principalmente, a dificuldade de acesso à internet.

\begin{abstract}
O principal problema é garantir que os alunos tenham acesso a conexões de internet de qualidade e acesso as próprias tecnologias (computadores, smartphone etc), mas isso está ligado intimamente a questão social. Portanto, não há como garantir que as TDIC sejam efetivas na educação até que as famílias tenham as condições mínimas para adquirir estas tecnologias e acessar internet de forma mais ampla. (INF. 7)

$\mathrm{Na}$ minha opinião o ponto chave está no acesso dos estudantes. Muitos não possuem computador/celular com acesso. Às vezes é a bateria que não presta, às vezes a tela que está quebrada ou a memória muito cheia. Temos o recurso Escola Digital na rede estadual que é um AVA, mas os alunos não conseguem acessar. Passei duas semanas tentando fazê-los acessar uma primeira vez e mesmo assim não atingi nem $20 \%$ dos alunos. Mesmo pelo WhatsApp, muitos não conseguem entender aquele espaço como uma sala de aula. (INF. 13)

$\mathrm{O}$ país é muito desigual. O que mais dificulta essas ações é a falta de acesso à internet e a aparelhos compatíveis com os meios. (INF. 27).

Em relação aos aspectos negativos, como leciono em escola pública, conheço a realidade de alguns alunos, muitos não possuem um plano de internet para usufruiu das tecnologias, tampouco um notebook para realizar suas atividades. Na verdade, uma parte usa o celular, ou, precisa compartilhar um notebook com seus familiares. Não estou considerando, neste relatório, outros problemas que também interferem na vida do estudante. (INF. 36).
\end{abstract}

Os três informantes elencados demonstram que a maior dificuldade no uso das tecnologias se dá no acesso que os estudantes têm não só aos recursos de infraestrutura (computadores, notebooks, celulares, tablets), mas à própria rede de internet. Essa é uma questão que extrapola as condições pessoais, de conhecimento dos sistemas, ou de interesse e motivação, é uma questão social, como afirma o informante 7. A desigualdade social e econômica do país não permite o acesso igualitário de todos os estudantes ao que está sendo produzido e veiculado pelos docentes. Sem essas condições mínimas, que caberiam ao estado prover, não há como garantir a continuidade do vínculo com a escola, do acesso ao conhecimento e da manutenção da formação escolar. Mesmo reconhecendo, como demonstram os dados do censo escolar apresentados em tópico anterior, que a maioria dos estudantes possui celulares, nem todos os equipamentos têm condições de acesso à rede, pois 
isso depende da qualidade de internet que possuem, e os planos de dados são caros no país. Por isso, até o aplicativo mais utilizado pelos estudantes, o WhatsApp ${ }^{\circledR}$, quando usado para fins escolares, não atinge a maior parte dos estudantes, como reitera o Informante 13.

Os informantes da região Norte do país apresentam uma dificuldade ainda mais evidente quanto ao acesso:

O Ensino a distância no Sistema modular de Ensino (SOME) pois na maioria das localidades não há energia elétrica $24 \mathrm{~h}$. As que tem há falta de constante do fornecimento de energia. A grande maioria das localidades não tem acesso à internet. As que porventura tem, são poucos moradores que possuem e de péssima qualidade. A Grande maioria das Escola não TV, não tem parabólica e nem telefones. Desse modo fica inviável o de tecnologia de informação. Os poucos recursos tecnológicos utilizados são de propriedade do próprio professor. (INF. 47).

A diversidade regional do Brasil também se evidencia no que tange aos problemas de infraestrutura tecnológica. Na região Norte nem mesmo a eletricidade é garantida de forma permanente nas cidades mais longínquas, havendo quedas constantes de oferta, conforme relato do Informante 47. Nesse sentido, fica ainda mais complexa a oferta de atividades por meio da internet. A televisão aberta poderia ser uma possibilidade, nesses casos, no entanto, nem mesmo há parabólicas suficientes para o atendimento a todos os estudantes. O relato desse informante põe a nu a desigualdade do país.

Sendo esse aspecto do acesso o mais evidente ressaltado pelos docentes, outros transparecem em seu relato, como a falta de motivação ou de interesse.

[...] durante a pandemia, mesmo que seja uma opção, os alunos têm extrema dificuldade com cronogramas, horários específicos de estudos, prazos e motivação. Muitos destes problemas estão relacionados a estrutura familiar, e questões sociais típicas de famílias carentes. (INF. 7)

O uso das TDIC aplicado no ensino remoto dos anos iniciais é bastante difícil, pois os alunos não possuem autonomia para o desenvolvimento das atividades, como também desenvoltura com uso das tecnologias, dependendo da parceria dos responsáveis, que, por sua vez, demonstram-se minimamente interessados na mediação das atividades, visto a dificuldade em manusear às tecnologias e também por portarem aparelhos celulares com baixa capacidade de memória, que por vezes não comporta novos aplicativos e/ou apaga arquivos que eventualmente são enviados em grupos de WhatsApp. (INF. 25).

$\mathrm{O}$ aspecto negativo é a disponibilidade de internet pelos alunos. Baixa qualidade ou ausente. (INF. 48).

Os relatos dos docentes abordam ainda os problemas familiares que cercam os estudantes, alguns relativos à sua condição socioeconômica, a falta de autonomia e desenvoltura no uso das tecnologias, a dependência dos equipamentos de uso dos pais, e a qualidade dos aparelhos que eles utilizam. Todos esses elementos geram desmotivação, desinteresse e falta de assistência às atividades veiculadas por meio das tecnologias. Novamente, todos os relatos são retratos das condições de desigualdade social do país. O 
informante 59 indica que a falta de desenvoltura dos pais dos estudantes do Ensino Fundamental também pode interferir diretamente no interesse dos estudantes:

[...] percebi que muitos pais de alunos demonstraram dificuldades para acessar as aulas (6 e 7 anos) requerendo uma atenção maior por parte da escola. No início das videoaulas ao vivo, foi perceptível que poucos alunos (principalmente no Ensino Médio) participaram, possivelmente por acreditar que a pandemia seria algo passageiro, contudo, após a renovação da suspensão das aulas criou-se a concepção de que a situação era mais séria do que imaginaram, logo, passaram a frequentar as aulas e realizar as atividades. (INF. 59).

As condições da pandemia, que geraram incertezas constantes, principalmente devido à falta de esforço governamental ao estabelecer uma política voltada para as especificidades do momento, também interferiram nas atitudes e na motivação dos estudantes em cumprir as atividades veiculadas por meio das TDIC. As ações políticas foram sendo tomadas muito mais pelos governos estaduais, sem nenhum apoio da União, o que gerou controvérsias, descrédito e insegurança quanto à durabilidade do período de isolamento social.

$\mathrm{O}$ relato dos docentes que atuam no Ensino Fundamental aponta a falta de desenvoltura das crianças com o uso das tecnologias para estudo, além de ressaltar a necessidade de interação social das crianças, como lembra o Informante 61: "Porém existe a necessidade do contato humano com as crianças. Percebo que existem dificuldades na realização das atividades em casa, porque as crianças não veem os pais como professores."

Um outro aspecto que surge também são as dificuldades de acesso e uso às TDIC pelos professores:

\footnotetext{
Muito importante se os alunos e professores tiverem acesso. (INF. 76).

Falta de recursos tecnológicos do Estado, nenhum suporte, temos que usar recursos de uso pessoal. (INF. 89).

Quanto ao trabalho docente, temos que usar os recursos digitais que possuímos e recebemos centenas de mensagens nos grupos do WhatsApp e no Google Sala de Aula. O trabalho docente foi transferido para os nossos lares, não respeitando nossa privacidade ou logística familiar. (INF. 90).
}

Os relatos indicam que os professores têm feito esforço para a realização das atividades, no entanto, não contam com infraestrutura adequada e não recebem suporte tecnológico do Estado, contando apenas com seus recursos próprios para a elaboração de atividades diversas, que se somam às atividades domésticas, realizadas de forma acumulada dentro do ambiente doméstico no contexto da pandemia, o que pode inviabilizar, por exemplo, a adequada elaboração de videoaulas. Essas questões ligadas às dificuldades docentes fizeram emergir nos relatos uma segunda categoria geral ligada à capacitação dos docentes. 


\subsection{Capacitação para uso das TDIC}

As TDIC são criadas e aplicadas no cotidiano de forma cada vez mais rápida, exigindo conhecimentos e habilidades cada vez mais complexos. Sua utilização gera inúmeras mudanças de hábito, elas aceleram a comunicação entre as pessoas, interferem no trabalho e, embora diminuam distâncias, podem ser elementos de exclusão social quando não se tem acesso ou mesmo quando não se tenha familiaridade com seu uso. Seu impacto na educação tem sido sempre permeado por conflitos, assim como gerador de novas formas de relação na mediação professor/conteúdo/estudante. Concordamos com Gadotti (2003, p.312) quando afirma que "O conhecimento novo é resultado de um longo processo em construção do indivíduo". Como conhecimentos e instrumentos novos, a aplicação das TDIC no ensino pode ser um instrumento de grande valia para o professor, mas exige compreensão de que novas formas de ensinar e aprender exigem também novas metodologias e novas formas de planejar e desenvolver o ensino e a aprendizagem. Ocorre que a pandemia pegou a todos de forma muito rápida e não houve um preparo, capacitação ou mesmo reflexão acerca da repentina implantação do ensino remoto.

Para usar as TDIC no ensino não basta ter as ferramentas à disposição, pois elas implicam na aptidão dos professores para seu uso. Nesse sentido, a capacitação dos docentes é elemento fundamental para que consigam integrar no seu planejamento essas tecnologias compreendendo suas possibilidades de promover a interação, a comunicação, a busca de informações, a construção do conhecimento. Essa capacitação não pode ser pontual, ela precisa ser implementada como processo. Retomando Nóvoa (2002), lembramos que a formação continuada perpassa a possibilidade de construção de projetos na escola, a criação de redes de trabalho em coletividade, a partilha de conhecimentos e de experiências. Assim, investir na formação dos professores já era uma necessidade reiterada por estudiosos da área desde há muito, com o evento da pandemia, isso se torna ainda mais premente e necessário. Assim como se torna importante investir na infraestrutura tecnológica acessível ao professor e aos estudantes.

Emerge dos relatos dos docentes que responderam à pesquisa a relevância da capacitação para o adequado uso das TDIC durante a pandemia. O aspecto que mais chama atenção quanto à capacitação, é a necessidade reiterada por muitos dos informantes para ter alguma formação relativamente ao uso das TDIC:

Com certeza, a capacitação dos docentes e acesso à internet de qualidade nas escolas, no mínimo ajudaria esse processo de transição forçada. (INF. 15) 
Adaptar-se requer conhecimentos e treinamentos sem garantia de êxito devido à dificuldade de acesso por parte dos alunos. (INF. 24)

[...] percebo que preciso desenvolver um letramento digital de qualidade. (INF.36)

A falta de capacitação é percebida eventualmente como uma necessidade sentida pelo docente a partir da pandemia. Essa necessidade surge sob a responsabilidade do próprio docente, que se move em direção a uma formação, como afirma o Informante 36: "Para tanto, fiz minha inscrição no curso promovido pelo IF de Curras Novos/RN", ou pode transparecer como uma demanda de classe:

Acredito que todos os professores deveriam ter acesso a um curso ou materiais que
o auxiliarem a desenvolver aulas com uso da tecnologia, para que em momentos
como estes se sintam mais seguros. (INF. 59).
Há uma necessidade urgente que as secretarias de educação realizem cursos e
disponibilize condições para acontecer de fato o que ainda não é realidade na
maioria das escolas. (INF.60).
Outro fator é que o professor precisa ser capacitado para tal exercício, não pode
só dizer que a gente vai fazer pq o governo quer, aulas presenciais são bastante
diferentes. (INF.71).

A necessidade de formação e de maior envolvimento com as TDIC para o ensino é pauta da maioria dos relatos dos respondentes. Os fragmentos aqui apresentados demonstram essa perspectiva, pois apenas alguns professores indicaram já possuir conhecimentos sobre o tema.

Emergem, também, dos relatos, a revolta ou a preocupação por estar sendo obrigado a produzir conteúdo e material sem ter passado pela devida capacitação.

Estou nesse processo, nos jogaram sem nenhuma capacitação e querem que façamos de conta que estamos dando aula. (INF.18).

Precisamos de treinamento especializados para docentes, discentes e demais colaboradores escolares. (INF.80).

Os relatos dos professores reconhecem, portanto, sua insegurança diante do uso das TDIC, demonstram a preocupação com o acesso dos estudantes e clamam por uma formação que atenda às necessidades que emergem dessa nova realidade.

\section{Considerações finais}

Este texto traz os resultados parciais de uma pesquisa desenvolvida em colaboração por professores e pesquisadores do Grupo de Pesquisa Multirreferencialidade, Educação e Linguagem (GPMEL) do IFRN, aprofundando a parceria entre o IFRN e o Centro de Investigação em Educação e Psicologia da Universidade de Évora, Portugal. A pesquisa mais ampla tem o objetivo geral de conhecer e compreender os aspectos do uso das Tecnologias da Informação e da Comunicação no contexto da pandemia Covid-19 a partir dos relatos de docentes da Educação Básica (Ensino Fundamental e Ensino Médio) no Brasil. 
Neste artigo, apresentamos os resultados da aplicação de um questionário aplicado via Google Forms a professores da Educação Básica pública no Brasil. A ênfase, aqui, é dada aos relatos dos docentes, procurando compreender o que mais os afetou e afeta no exercício da docência durante a pandemia Covid-19.

Para compreender os relatos e contextualizá-los fez-se necessária uma retomada dos dados sobre a realidade escolar no Brasil a partir das estatísticas do censo do IBGE e do censo da educação básica, do INEP. Os relatos dos docentes reiteram a realidade dos dados e apresentam a diversidade e a profunda desigualdade que constituem a realidade brasileira.

As principais categorias elencadas a partir do relato dos docentes se concentrou nos aspectos positivos e negativos do uso das TDIC durante a pandemia. Entre os aspectos positivos, o aprendizado e as possibilidades de inovação nas práticas pedagógicas desses docentes. Quanto aos aspectos negativos, fica evidente a grande preocupação dos professores quanto às dificuldades de acesso de seus estudantes aos recursos tecnológicos.

Uma segunda categoria emergiu também do discurso dos docentes, retratando a sua necessidade de capacitação para o uso das TDIC. A capacitação oferecida eventualmente oferecida pelas Secretarias de estado e pelos municípios surge nos relatos como insuficientes, nem sempre atendendo às necessidades dos docentes. $\mathrm{O}$ que emerge dos discursos é que muitas vezes essas capacitações concentraram-se no treinamento para uso dos recursos e menos na reflexão acerca da educação por meio remoto. Também transparece dos relatos a necessidade de investimento por parte dos próprios docentes em infraestrutura tecnológica para a realização de atividades, pois esses recursos não foram providos pelo poder público.

Este artigo apresenta apenas um recorte dos dados recolhidos, no entanto, já deixa evidente as questões mais prementes do ensino remoto no Brasil e a angústia dos docentes durante a pandemia iniciada em 2020.

\section{Referências}

ABRAHÃO, M. H. M. B. Memória, narrativa e pesquisa autobiográfica. Revista História da Educação. ASPHE/FAe/UFPel, Pelotas, n.14, p.79-95, 2003. Disponível em: https://seer.ufrgs.br/asphe/article/view/30223/pdf. Acesso em: 15 set. 2020.

BARDIN, Laurence. Análise de conteúdo. São Paulo: Edições 70, 2011

BUTLER, J. Traços humanos nas superfícies do mundo. [S.1.], 2020. Disponível em: https://www.n-1edicoes.org/textos/75. Acesso em: 17 de mai. de 2020. 
COSTA, C. L. da., CAVALCANTE, I. F. Alteridades(s), escritas de si e reflexão: olhares cruzados sobre a formação de professores em Portugal e no Brasil. Revista Brasileira de Educação de Jovens e Adultos. vol. 5, n ${ }^{\circ}$ 10, 2017.

DAVIS, M. (Org.). Coronavírus e a luta de classes. Brasil: Terra sem Amos, 2020.

FISON, L. M. B., SIMÃO, A. M. da V. (2020). Histórias de vida em pesquisa (auto) biográfica: circuito que inclui tempos, lugares e autorregulação da aprendizagem. Revista Brasileira de Pesquisa (Auto)Biográfica. Salvador, v. 05, n. 13, p. 71-90, 2020. Disponível em: https://revistas.uneb.br/index.php/rbpab/article/view/7508 Acesso em: 10 dez. 2020.

GADOTTI, Moacir. História das Ideias Pedagógicas. São Paulo: Ática, 2003

IBGE. (2018). Pesquisa Nacional por Amostra de Domicílios (PNAD). Disponível em https://www.ibge.gov.br/estatisticas/sociais/populacao/17270-pnad-

continua.html?edicao $=27138 \& \mathrm{t}=$ resultados Acesso em: 18 mai. de 2020 .

INEP. Censo Escolar. Sinopses estatísticas 2019. 2019. Disponível em: http://portal.inep.gov.br/documents/186968/0/Notas+Estat\%C3\%ADsticas++ Censo+da+Educa $\%$ C3\%A7\%C3\%A3o+B\%C3\%A1 sica+2019/43bf4c5b-b4784c5d-ae17-7d55ced4c37d?version=1.0 Acesso em: 18 mai. de 2020.

KRENAK, A. O amanhã não está à venda. São Paulo: Companhia das Letras, 2020.

LATOUR, Bruno. Imaginando gestos que barrem o retorno ao consumismo e à produção insustentável pré-pandemia. 2020. Disponível em: https://climainfo.org.br/2020/04/02/barrar-producao-insustentavel-e-onsumismo/ Acesso em: 17 mai. 2020.

NÓVOA, Antonio. (Coord.). Os professores e sua formação. Lisboa-Portugal: Dom Quixote, 2002.

PASSEGI, M. C., SOUZA, E.C. de, VICENTINI, P.P. Entre a vida e a formação: pesquisa (auto) biográfica, docência e profissionalização. Educação em Revista. Belo Horizonte, v.27, n.1, p.369-386, abr. 2011. Disponível em: https://www.scielo.br/pdf/edur/v27n1/v27n1a17.pdf. Acesso em: 25 ago. 2020.

TODOS PELA EDUCAÇÃO. Nota técnica: ensino a distância na educação básica frente à pandemia da Covid-19. 2020. Disponível em: https://www.todospelaeducacao.org.br/ uploads/ posts/425.pdf?1730332266=\&ut $\underline{m}$ source $=$ conteudo-nota\&utm medium=hiperlink-download Acesso em: 18 mai. de 2020 .

VIANA, Clara. São cada vez menos alunos que podem contar com a escola para ter acesso ao mundo digital. 2019. Disponível em: https://www.publico.pt/2019/02/03/sociedade/noticia/sao-menos-alunos-podemcontar-escola-acesso-mundo-digital-1860501 Acesso em: 25 ago. de 2020.

VINCENT-LANCRIN, S., et al. Measuring Innovation in Education 2019: What Has Changed in the Classroom?. Educational Research and Innovation. OECD Publishing, Paris, 2019. Disponível em: https://doi.org/10.1787/9789264311671-en. Acesso em: 25 ago. de 2020. 
Autores:

Ilane Ferreira Cavalcante

Graduação em Letras pela Universidade Federal do Rio Grande do Norte (1991), mestrado

em Estudos da Linguagem (1996) e doutorado em Educação (2002) pela mesma universidade. Atualmente é professora de Língua Portuguesa do Instituto Federal de Educação, Ciência e Tecnologia do Rio Grande do Norte, atuando no Programa de Pósgraduação em Educação Profissional (PPGEP). Lidera o grupo de Pesquisa Multirreferencialidade, Educação e Linguagem (GPMEL) desde 2011. Tem experiência na área de Letras e Educação, com ênfase em literatura e história da educação, atuando principalmente nos seguintes temas: educação profissional, educação a distância, formação de professores, gênero e literatura.

ilanecfc@gmail.com

https://orcid.org/0000-0002-1783-9879

Instituto Federal do Rio Grande do Norte (IFRN)

Natal, Brasil

João Paulo de Oliveira

Centro de Investigação em Educação e Psicologia da Universidade de Évora (CIEP-EU)

Évora, Portugal

jprussasce@gmail.com

https://orcid.org/0000-0002-6582-8402

Conceição Leal da Costa

Centro de Investigação em Educação e Psicologia da Universidade de Évora (CIEP-EU)

Évora, Portugal

Doutoramento: Ciências da Educação/Aprendizagens, Formação e Desenvolvimento de Professores (Universidade de Évora - 2015). Mestrado: Administração

Educacional/Ciências da Educação (Universidade de Évora - 2000)

Licenciatura em Ensino de Física e Química (Universidade de Évora - 1990)

Interesses de pesquisa: Aprendizagem, Formação e Desenvolvimento Profissional;

Narrativas e Histórias de Vida em Educação

Professora Auxiliar do Departamento de Pedagogia e Educação (DPE) da Universidade de Évora. Investigadora do Centro de Investigação em Educação e Psicologia da Universidade Évora. Diretora da Pós-graduação em Docência e Investigação no $1^{\circ} \mathrm{Ciclo}$ do Ensino

Básico. Membro da Comissão Executiva e de Acompanhamento do Mestrado em Educação Pré-escolar e Ensino do $1^{\circ} \mathrm{CEB}$. Presidente do Conselho Coordenador da Prática de Ensino Supervisionada. Perita de Avaliação Externa TEIP. Membro da Sociedade

Portuguesa de Ciências da Educação; Membro do Forum Português de Administração

Educacional; tem experiência na área da Administração Educativa em estruturas do

Ministério da Educação, em escolas e na universidade, nomeadamente, enquanto membro

da Direção do DPE.; investigadora do CIEP|UE (Portugal). Colaboradora estrangeira do

CIRBE (França); Colaboradora estrangeira do Grupo de Estudos e Pesquisas

Autobiográficas, do(a) Universidade Estadual Vale do Acaraú (Brasil) https://orcid.org/0000-0003-3299-6845

mcl@uevora.pt 